\title{
Ischaemic optic neuropathy in chronic simple glaucoma
}

\author{
*I. S. BEGG, S. M. DRANGE, AND V. P. SWEENEY
}

From the Department of Ophthalmology and the Division of Neurology, Department of Medicine, University of British Columbia; the Glaucoma Clinic and Division of Neurology, Vancouver General Hospital; and the Department of Ophthalmology, Shaughnessy DVA Hospital, Canada

The characteristic visual field changes of early glaucoma occur in the Bjerrum area of the visual field and are related to damage of the arcuate nerve fibre bundles (Traquair, I944; Harrington, 1964a). The susceptibility of these nerve fibre bundles at the optic nerve head to functional changes, whether reversible, relative, or absolute, is the prime characteristic feature of the glaucomatous process, although it is not exclusive to this disease. A vascular cause for this damage has been postulated by many authors (DukeElder, 1962; Gafner and Goldmann, 1955; Harrington, 1959; Feldman, Sweeney, and Drance, 1969), but in some instances a metabolic derangement of the neurone may influence its susceptibility to damage from reduction in blood supply (Armaly, I969).

In previous communications we have described an acute ischaemic change in the optic nerve head characterized by a symptomless haemorrhage on a sector of the disc and a corresponding fresh absolute arcuate scotoma, a sequence of events hitherto not described in chronic simple glaucoma and probably of considerable importance in the natural history of the disease (Drance and Begg, 1970; Begg, Drance, and Sweeney, 1970). The present report amplifies the concept of ischaemic optic neuropathy in the glaucomatous process and shows that it can be responsible in some eyes for the conversion of ocular hypertension to chronic simple glaucoma.

\section{Material and methods}

The seven cases were selected from a group of over thirty patients as typical examples. In addition to full ophthalmological evaluation, the general assessment consisted of an examination by a vascular neurologist, and the following additional investigations were carried out:

(I) Full blood count, erythrocyte sedimentation rate, packed cell volume

(2) Serum electrolytes, cholesterol, plasma proteins, blood urea nitrogen

(3) Serum P.B.I., $\mathrm{T}_{4}$ by column

(4) Fasting blood sugar and 2 hrly p.c.

(5) Glucose tolerance test in selected patients

(6) Coagulability studies in selected patients

(7) Venereal disease research laboratory tests

(8) Electrocardiogram

(9) $X$-ray chest, skull, and orbital foramina 


\section{Case reports}

Case 1, a 55-year-old man, was found to have chronic simple glaucoma in 1963 with intraocular pressures of $3 \mathrm{r} \mathrm{mm} . \mathrm{Hg}$ in both eyes. He was slightly myopic with normal visual acuity. There was a family history of glaucoma on his mother's side. Gonioscopy revealed a wide open angle with a heavy pigmentation. The coefficient of outflow facility on therapy was $0 \cdot 19$ in both eyes.

Examination in 1965 showed that the right disc was pale and pathologically cupped and that the left disc was suspiciously cupped. Visual field examination showed a lower arcuate scotoma in the right eye and a full field in the left eye. He was treated with miotics, epinephrine, and Diamox, but the latter was discontinued in 1966 when renal calculi developed. Despite the fact that the treated ocular tension rose only to $20 \mathrm{~mm} . \mathrm{Hg}$ in the right eye and $18 \mathrm{~mm} . \mathrm{Hg}$ in the left, an upper paracentral scotoma developed in the right eye and a lower absolute scotoma adjacent to the horizontal meridian in the inferior Bjerrum area in the left. Field loss continued during the next 2 years.

In 1968 , the tension rose to $25 \mathrm{~mm} . \mathrm{Hg}$ in both eyes and a Scheie's operation was carried out in the right eye; but 4 months later therapy was resumed.

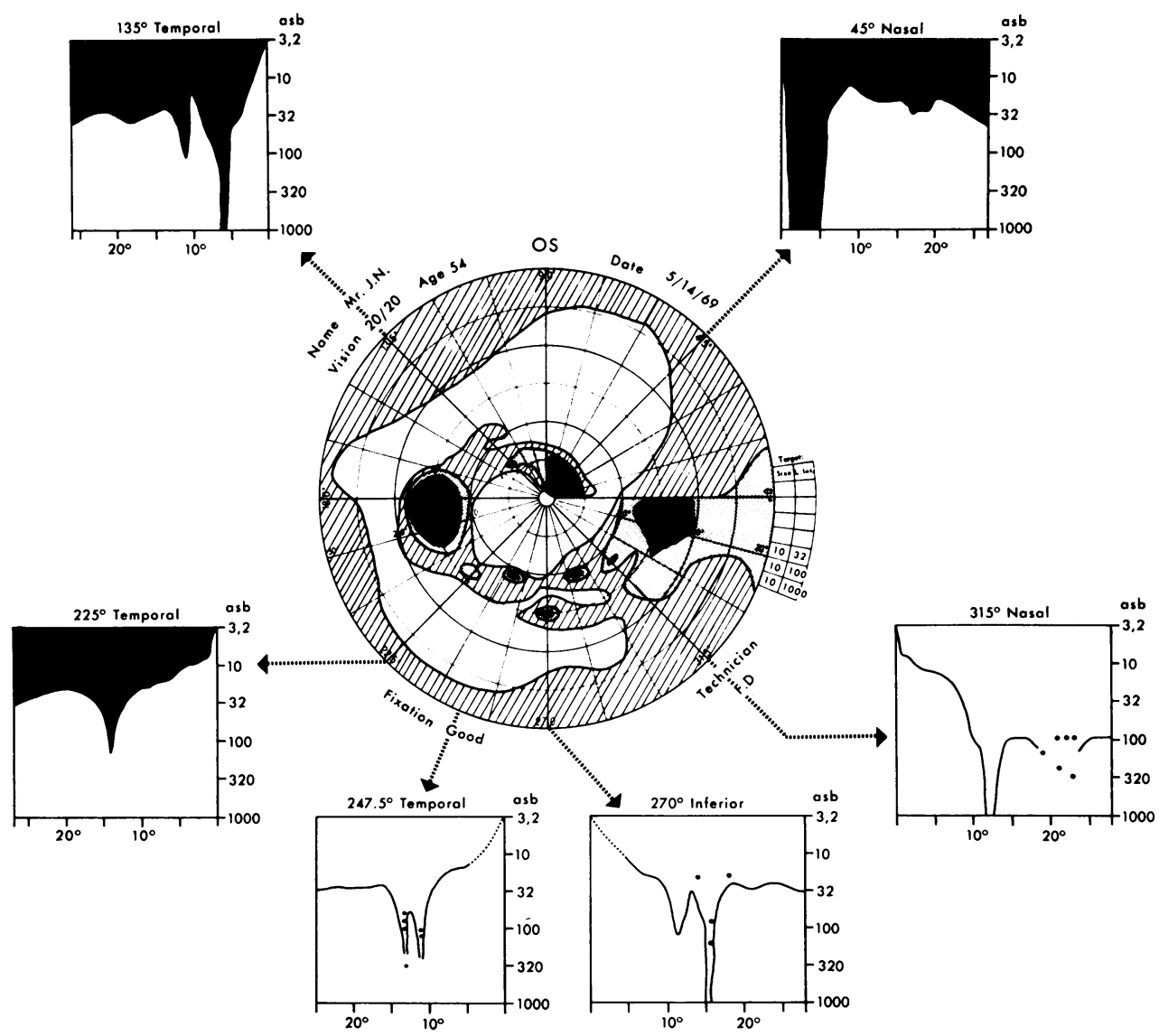

FIG. I Case I. Static and kinetic field, showing superior arcuate scotoma with absolute paracentral nucleus in the nasal quadrant, and inferior arcuate scotoma with multiple absolute nuclei 
A general assessment in 1968 showed that the patient was in good general health and that there were no signs of diabetes, or evidence of cardiac, cerebrovascular, or peripheral vascular insufficiency. No bruits over the internal carotid arteries were heard, but the blood pressure was only I 10/76.

The visual field of the left eye in May, 1969, is shown in Fig. I. In October, 1969, a linear haemorrhage at 5 o'clock on the neuroretinal rim of the left disc was observed. The cup:disc ratio was 0.6 in the right eye and 0.7 in the left. Static field examination of the left eye showed a slight extension of the superior absolute nucleus as well as a fresh scotoma inferiorly, adjacent to the horizontal meridian, extending peripherally from the $20^{\circ}$ isopter (Fig. 2). The intraocular pressures in the preceding months had varied from 20 to $28 \mathrm{~mm}$. Hg.

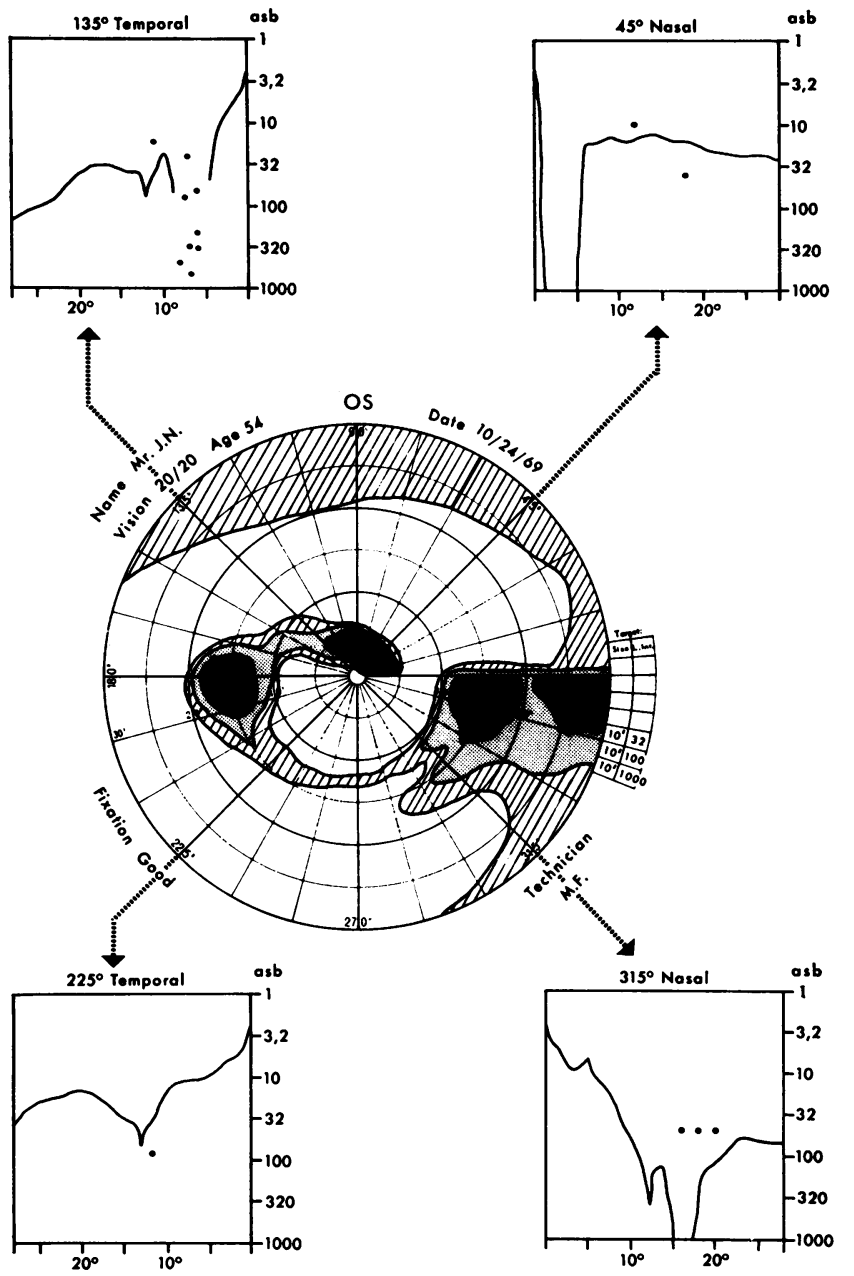

FI G. 2 Case I. Static and kinetic field, showing fresh extension of absolute nucleus in superior arcuate scotoma, and fresh absolute scotoma inferiorly adjacent to horizontal meridian

Case 2, a 67-year-old woman, was seen in October, 1968, with a history of chronic simple glaucoma of at least 4 years' duration. Her highest intraocular pressures were $30 \mathrm{~mm} . \mathrm{Hg}$ in both eyes. There was a family history of glaucoma. A drainage procedure had been carried out in the right eye in 1965 and the intraocular pressure thereafter remained within the normal range, although lens opacities and postinflammatory adhesions had developed so that the right disc could not be seen. The left eye had been treated with 4 per cent. pilocarpine and Diamox with a diurnal tension peak up to $22 \mathrm{~mm} . \mathrm{Hg}$. The outflow coefficient in the left eye was $0 \cdot 13, \mathrm{Po} / \mathrm{G}=154$. There was deep excavation of the left disc, and a markedly narrowed inferior neuroretinal rim. The retinal arterioles showed marked irregularity and calibre variation, and there were arterio-venous crossing changes. 
Static field examination of the left eye in October, 1968, showed a relative superior paracentral scotoma in the nasal field (Fig. 3).
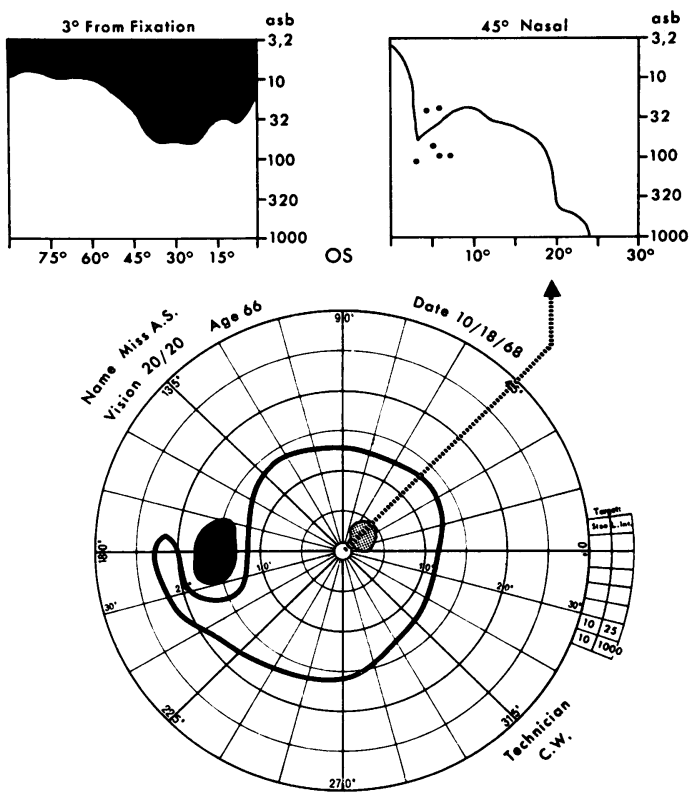

FIG. 3 Case 2. Static and kinetic field, showing relative paracentral scotoma close to fixation

A general assessment revealed that she had received intermittent treatment for mild hypertensio since $194^{2}$, but not during the period of ocular examinations. There was no history of cardiaci. ischaemia or peripheral vascular disease. In the past, she had experienced recurrent paroxysmat tachycardia in association with syncopal episodes but no attacks had occurred recently. On one occasion it was recorded that the blood pressure could not be measured at the time of the tachycardia. There was a past history of hysterectomy for malignancy, and cholecystectomy, but without hypotension on either occasion. Her blood pressure was 170/90. There was evidence of left ventricular enlargement. The internal carotid arteries had normal pulsation and no bruits.

In May, I969, a superficial, flame-shaped haemorrhage was observed in the 5 o'clock position on the neuroretinal rim of the left optic disc. The cup:disc ratio was 0.9 and the neuroretinal rim was almost transparent and virtually non-existent at 5 to 6 o'clock. Marked peripapillary atrophy surrounded the disc. The intraocular pressures were $12 \mathrm{~mm} . \mathrm{Hg}$ in the right eye and $20 \mathrm{~mm} . \mathrm{Hg} O$ in the left. Visual field examination showed an extension of the superior arcuate scotoma with a fresh small absolute nucleus. A fresh absolute scotoma in the inferior field was also present (Fig. 4). Treatment was changed to include phospholine iodide $0 \cdot 125$ per cent., epinephrine 2 per cent., and Diamox, and on this regime the intraocular pressures were reduced to $10 \mathrm{~mm} . \mathrm{Hg} \stackrel{\circ}{=}$ in the right eye and $15 \mathrm{~mm} . \mathrm{Hg}$ in the left, the outflow coefficients being $0 \cdot 29, \mathrm{Po} / \mathrm{C}=34$ in the right eye and $0 \cdot 27, \mathrm{Po} / \mathrm{C}=74$ in the left.

Another superficial haemorrhage was observed 3 months later at the left disc, overlying the neuro- $\mathcal{N}$ retinal rim and adjacent retina at 6 o'clock (Fig. I8). Visual field examination of the left eye showed N a marked deterioration, as the absolute nucleus of the superior arcuates cotoma had increased con- N siderably, and there was also a fresh absolute scotoma superiorly in the Bjerrum area (Fig. 5, overleaf). The intraocular pressure on this occasion was $16 \mathrm{~mm} . \mathrm{Hg}$ in the right eye, but it had risen to $26 \mathrm{~mm}$. $\mathrm{Hg}$ in the left.

An external trabeculectomy was carried out on the left eye in October, 1969 , and the intraocular $\stackrel{\oplus}{+}$ pressure has since remained well within the normal range. In March, 1970, a flame-shaped haem- 


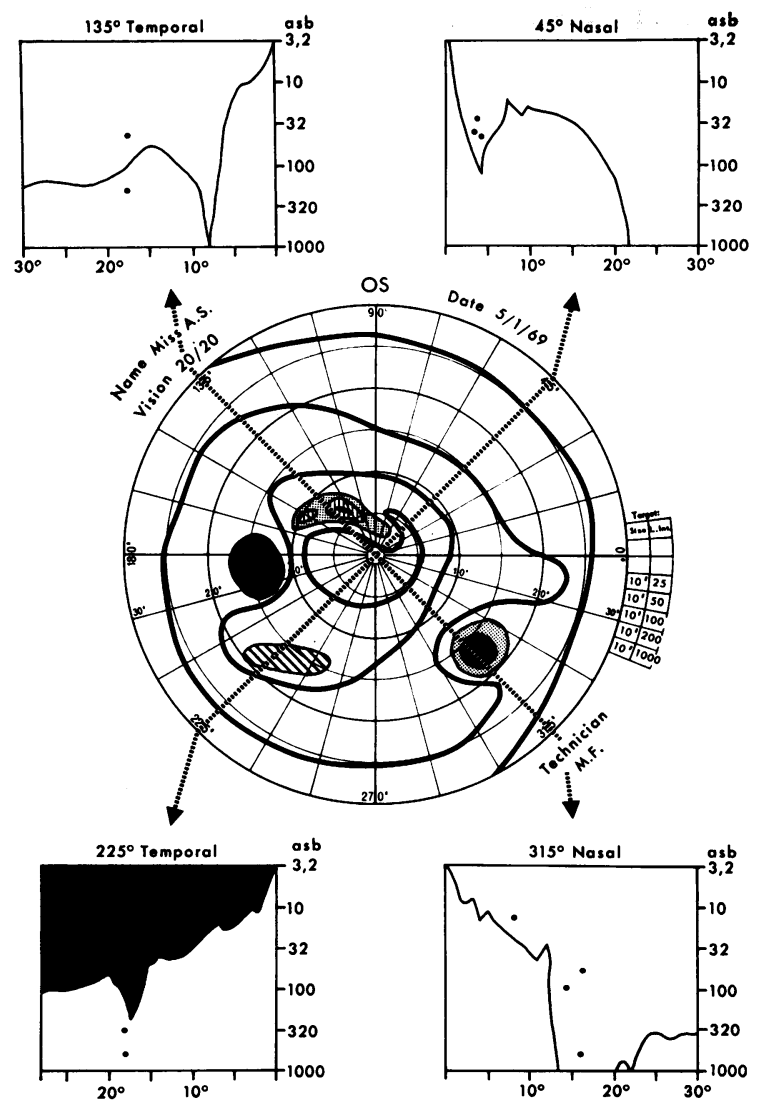

FIG. 4 Case 2. Static and kinetic field, showing fresh extension of superior arcuate scotoma with development of absolute nucleus; also fresh absolute scotoma in infero-nasal quadrant

orrhage was noted at 2.30 o'clock on the rim of the left disc. Visual field examination showed no fresh defect. The diurnal tension peak was $17 \mathrm{~mm} . \mathrm{Hg}$.

A general assessment was repeated in 1970 . There were no specific symptoms of vascular disease and no change in the patients physical state was observed. The blood pressure was 190/ro6.

Case 3, a 56-year-old woman, was found to have chronic open-angle glaucoma in December, ig66. The intraocular pressures were $26 \mathrm{~mm} . \mathrm{Hg}$ in the right eye and $30 \mathrm{~mm} . \mathrm{Hg}$ in the left, with widely open angles. Cupping of the optic discs was asymmetrical, the left being greater than the right. Visual field examination with the Goldmann perimeter revealed two small relative paracentral scotomata in the superior Bjerrum area of the left eye to a $1 / 2$ target. There was no family history of glaucoma.

Intraocular pressure levels were maintained, on the whole, just below $21 \mathrm{~mm} . \mathrm{Hg}$ on therapy. No progression of the visual field defect was observed. In fact, repetition showed the disappearance of the relative defects in 1967 . The relative paracentral scotomata were again demonstrated in 1968 to a $1 / 2$ target.

In June, I969, a superficial linear haemorrhage was observed at the margin of the left disc. It was situated at the 5 o'clock position, where the neuroretinal rim was narrowed and excavated. The cup: disc ratio was 0.6 in the right eye and 0.8 in the left. There was no significant peripapillary atrophy. The retinal arterioles were narrowed and straightened. Static field examination showed an absolute arcuate scotoma (Fig. 6). The intraocular pressures at this time were $19 \mathrm{~mm} . \mathrm{Hg}$ in 

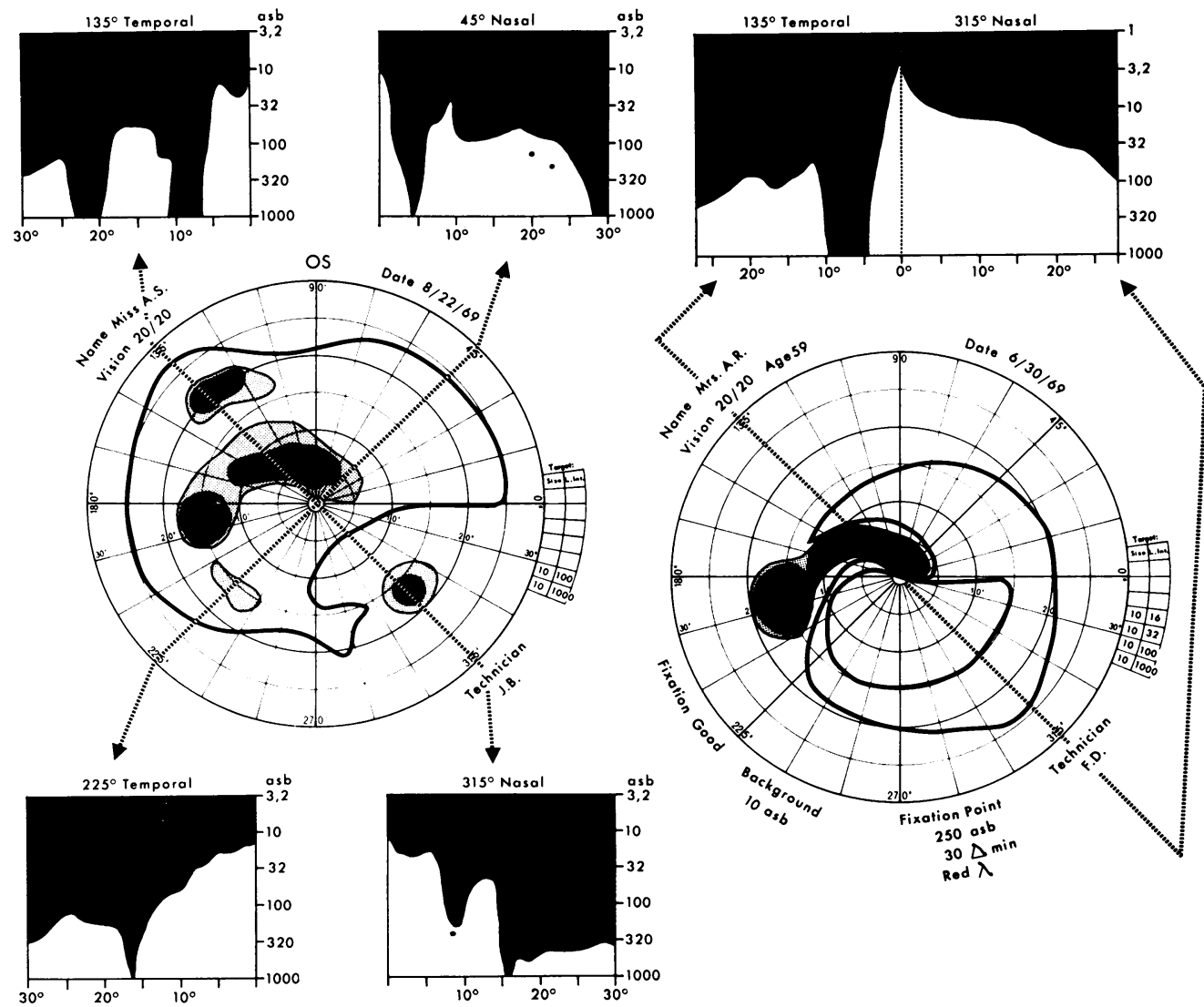

FIG. 5 Case 2. Static and kinetic field, showing considerable fresh extension of absolute nucleus of superior arcuate scotoma, and fresh absolute scotoma superiorly in

F I G. 6 Case 3. Static and kinetic field, showing fresh absolute arcuate scotoma

Bjerrum area

the right eye and $22 \mathrm{~mm} . \mathrm{Hg}$ in the left. A month later there was no sign of the haemorrhage but a local atrophy of the neuroretinal rim was observed.

In 1967 the patient underwent mastectomy for breast malignancy and that same year she first experienced occasional mild angina of effort, aggravated by anaemia which was successfully treated. She had experienced episodes of pain above the left eye, attributed to sinusitis and successfully treated by antral lavage. No internal carotid bruit was detected. The blood pressure was $160 / 90$. There had been no recent changes in her general medication. Repeated electrocardiograms showed sinus rhythm and severe left bundle branch block, indicating changes which suggested that myocardial infarction had occurred in August and October, 1969 .

Case 4, a 64-year-old woman, who had been examined yearly for presbyopic correction since 1963, was found to have a symptomless haemorrhage on the left optic cup in July, 1965. The intraocular pressures were $28 \mathrm{~mm} . \mathrm{Hg}$ in the right eye and $26 \mathrm{~mm} . \mathrm{Hg}$ in the left. Gonioscopy revealed wide open angles. Tangent field examination showed full fields. There was no family history of glaucoma. Treatment with 2 per cent. pilocarpine was started, but this was later changed to 4 per cent. pilocarpine, as the intraocular pressures ranged between 20 and $26 \mathrm{~mm}$. $\mathrm{Hg}$. 
In March, 1968, the right disc was physiologically cupped and there was excavation and atrophy of the neuroretinal rim of the left disc at 5 to 6 o'clock. There was moderate bilateral peripapillary atrophy. The retinal arterioles showed sclerotic changes. A visual field examination showed a full field in the right eye and an absolute superior arcuate-shaped paracentral scotoma in the left (Fig. 7).

The intraocular pressures remained within the normal range on therapy, but in August, 1969, a fresh haemorrhage was observed at the left disc. It was partly superficial, partly deep, and was situated on the neuroretinal rim at 2 o'clock (Fig. 8).

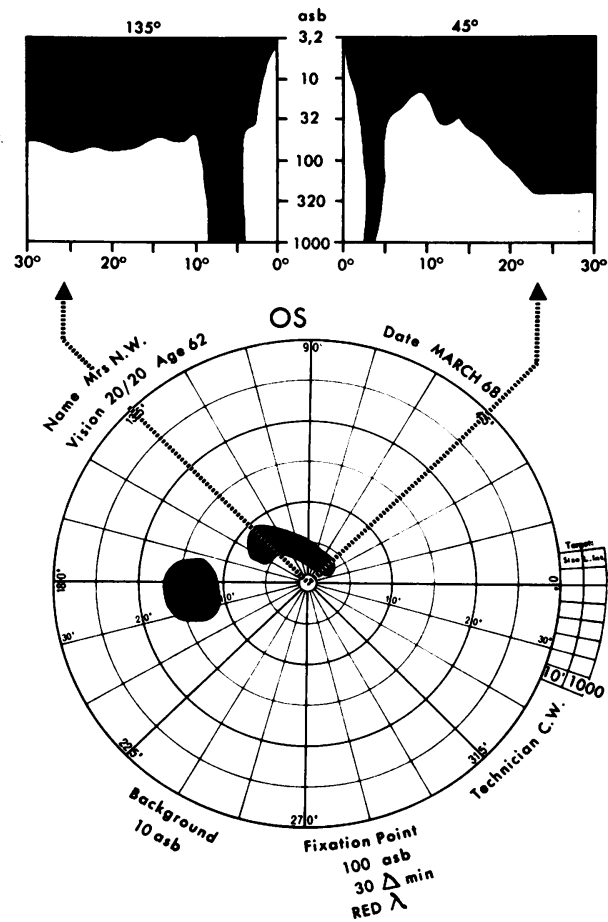

FIG. 7 Case 4. Static and kinetic field, showing absolute arcuate-shaped paracentral scotoma

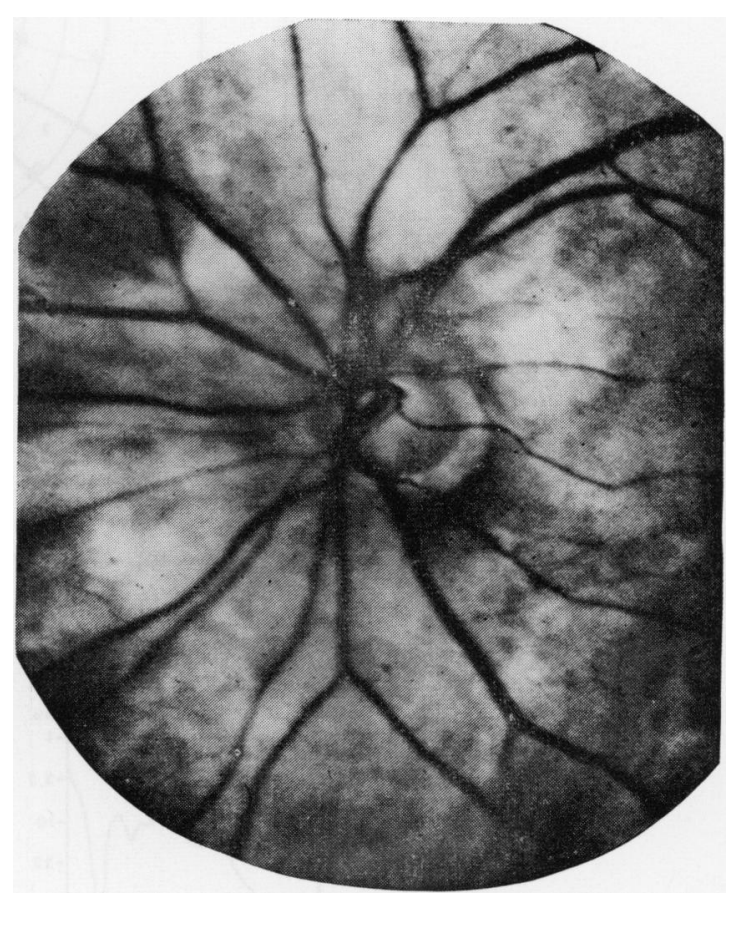

FI G. 8 Case 4. Left optic disc, showing a haemorrhage on the neuroretinal rim at 2 o'clock

Static visual field examination showed a fresh inferior arcuate-shaped scotoma with an absolute nucleus (Fig. 9, overleaf).

In February, 1970, a superficial haemorrhage was observed at the right optic disc, situated at 6.30 o'clock on the neuroretinal rim, which was otherwise pink and regular. Static visual field examination showed a small superior relative paracentral scotoma (Fig. 10) with a small nasal step in the more peripheral isopter (Fig. II, overleaf).

A general assessment in 1970 revealed a past history of mild hypertension which had been treated for several years, but she was receiving no medication at the time of the ocular examinations. Her blood pressure was $150 / 90$. There was a past history of peptic ulcers. A glucose tolerance test was positive. A platelet adhesiveness test was 77 per cent. (normal range 20 to 60 per cent.), consistent with a hypercoagulable state.

\section{S U M M ARY}

These four patients demonstrate the extension of existing glaucomatous defects or the occurrence of fresh defects in glaucomatous eyes accompanied by discrete linear haemorrhages on the optic nerve head. 

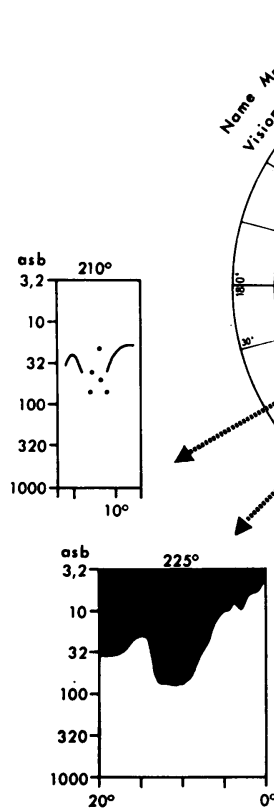

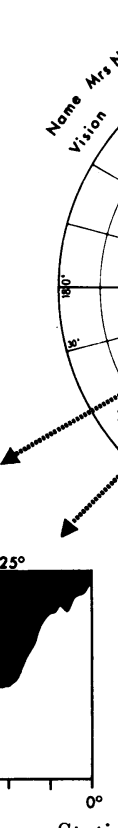

FIG. 9 Case 4. Static and kinetic field, showing fresh inferior arcuate scotoma with absolute nucleus

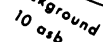

Fixation point 250 asb ${ }_{30} \Delta_{\text {min }}$

$\operatorname{Red} \lambda$
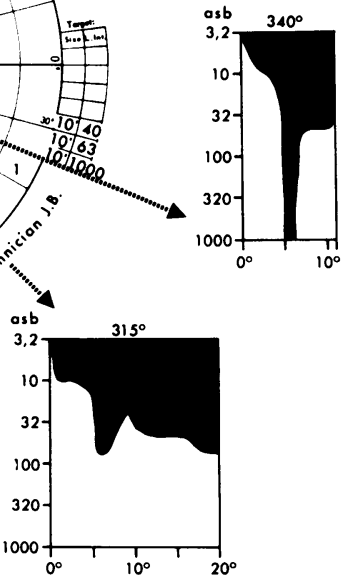

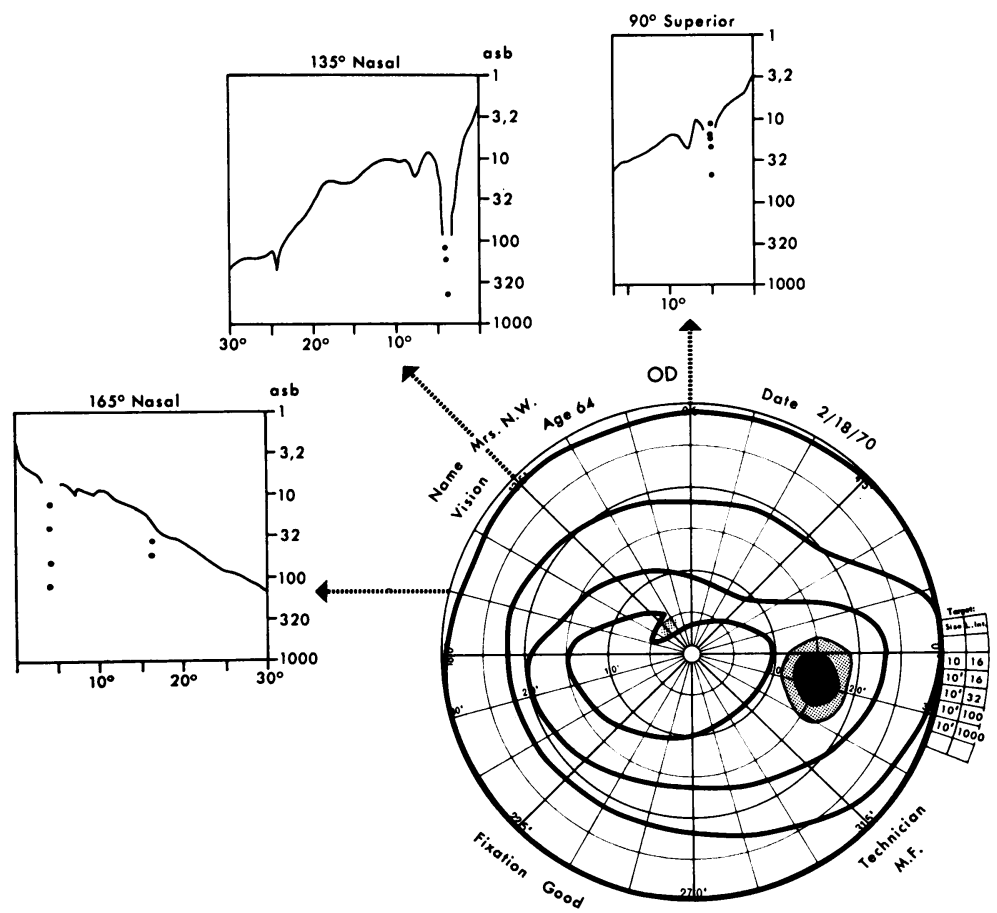

FI G. Io Case 4. Static and kinetic field, showing fresh, small, relative paracentral scotoma close to fixation 


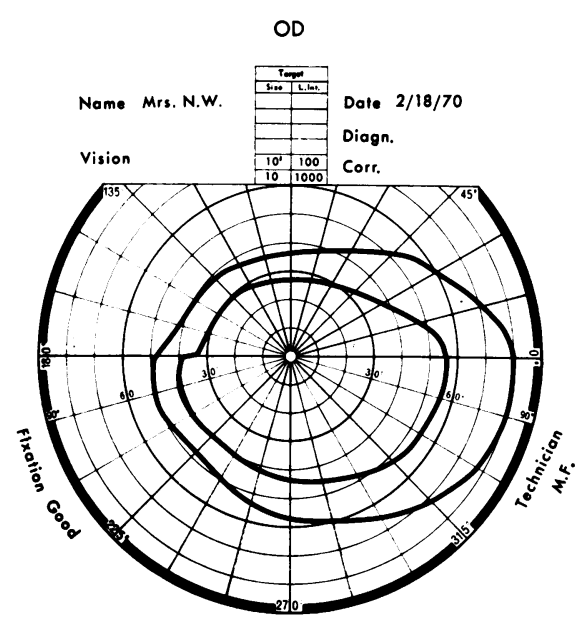

F I G. I I Case 4. Peripheral kinetic field, showing associated small nasal step (see Fig. 10)
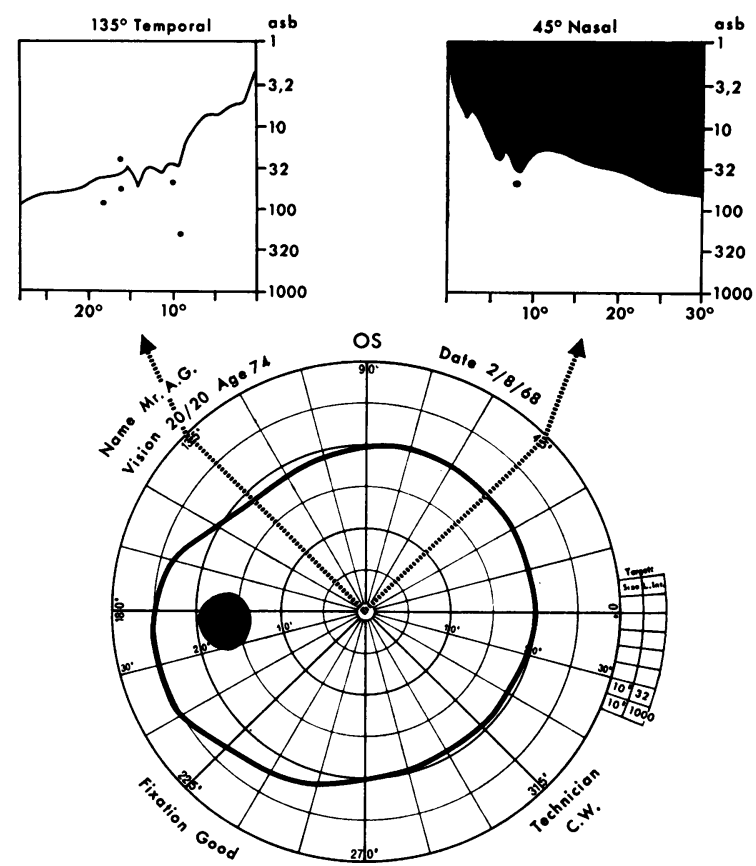

FIG. 12 Case 5. No field defect demonstrated by kinetic and static perimetry

Case 5, a 76-year-old man, attended for refraction in December, 1967, when ocular hypertension was first discovered. There was no family history of glaucoma. His mother had had a stroke when 40 years old. The intraocular pressures were $22 \mathrm{~mm} . \mathrm{Hg}$ in both eyes and the coefficient of outflow facility was 0.19 in the right eye and 0.29 in the left. Gonioscopy revealed wide open angles. Both optic discs showed wide physiological cupping. Static and kinetic visual field examination in February, 1968, revealed no defects (Fig. 12). At subsequent examinations during the next 10 months the intraocular pressures, untreated, ranged from 17 to $25 \mathrm{~mm} . \mathrm{Hg}$ in both eyes.

In October, 1968, an appearance of "neovascularization" was seen at 5 o'clock on the left optic disc. Static perimetric examination 2 months later showed an unusual relative paracentral scotoma in the superior Bjerrum area of the left eye (Fig. 13, overleaf). The visual field in the right eye remained intact. The intraocular pressures were maintained at about $15 \mathrm{~mm} . \mathrm{Hg}$ on a regime of 2 per cent. pilocarpine to both eyes.

A general assessment in January, 1969 , revealed no cerebrovascular or peripheral vascular symptoms apart from occasional "drop" attacks without loss of consciousness, which were attributed to probable impairment of the basilar system. There were no neurological symptoms. The blood pressure varied between $140 / 80$ and $160 / 90$, without postural hypotension. A glucose tolerance test showed no abnormality. An electrocardiogram showed left ventricular hypertrophy and an old anterior septal myocardial infarction.

In March, 1969, there was no sign of "neovascularization" but a flame-shaped haemorrhage was noted on the left disc. The arterioles showed sclerotic changes in both eyes. A month later a fresh haemorrhage was observed on the right disc at 5 o'clock. Visual field examination in May, 1969 , showed the appearance of a fresh absolute nucleus in the superior paracentral scotoma in the left eye, and a fresh absolute scotoma inferiorly adjacent to the horizontal meridian (Fig. I4, overleaf) but no field change in the right eye.

In October, 1969, the right optic disc remained unchanged, but marked notching of the neuroret inal rim of the left disc was noted at $\mathrm{I}$ and 5 o'clock. The cup:disc ratio was $0 \cdot 7$ in both eyes. 


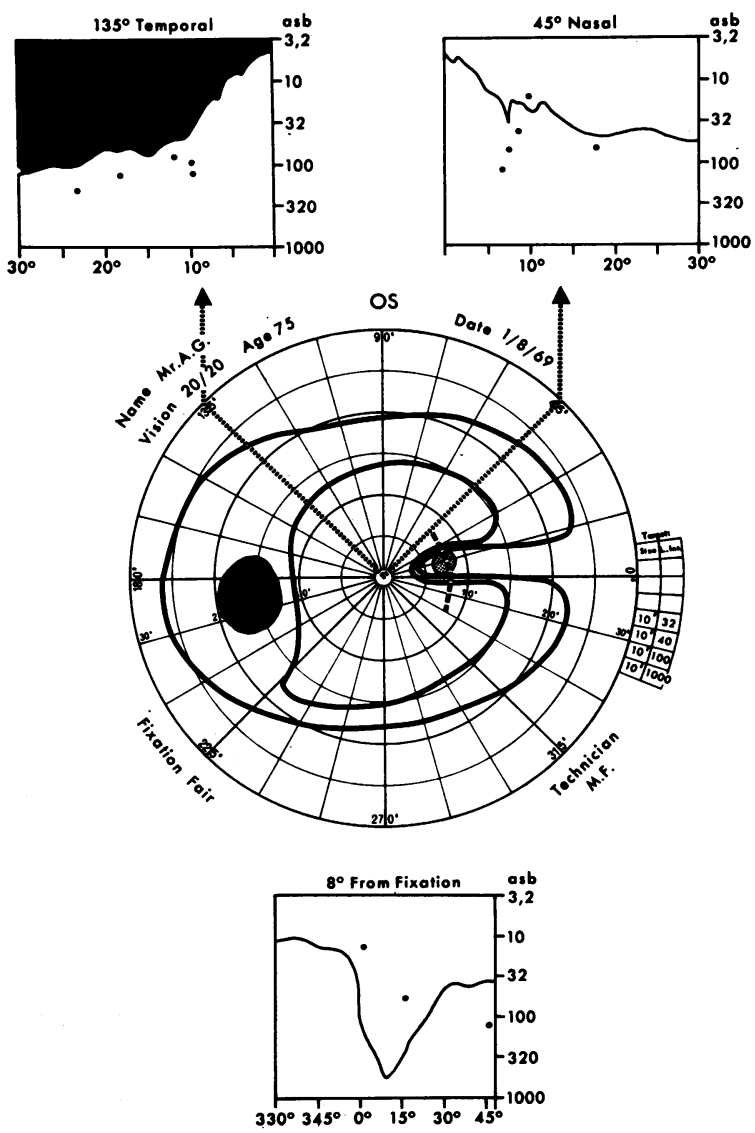

FIG. I3 Case 5. Relative paracentral scotoma above nasal horizontal meridian

Visual field examination showed a fresh absolute nucleus in the left eye, situated adjacent to the horizontal meridian 30J from fixation (Fig. 15, overleaf).

Another fresh haemorrhage at the right optic disc was noted in December, 1969. It was situated partly on the transparent neuroretinal rim and partly on the adjacent choroidal crescent at 5.30 o'clock. Static perimetric examination showed a small fresh absolute paracentral scotoma in the $90^{\circ}$ meridian, $14^{\circ}$ isopter of the superior Bjerrum area. Diamox was added to the local therapy. In April, 1970, a fresh haemorrhage was noted at 5.30 o'clock on the margin of the right disc, and there was marked narrowing of the rim at this site. Static perimetric examination of the right eye revealed a fresh small absolute scotoma in the $175^{\circ}$ meridian, with a small nasal step, as well as a peripheral depression in the $15^{\circ}$ meridian.

Case 6, a 73-year-old woman, had mild ocular hypertension which was first detected in $1964 \stackrel{\frac{D}{O}}{=}$ when the intraocular pressures were $22 \mathrm{~mm} . \mathrm{Hg}$ in the right eye and $20 \mathrm{~mm} . \mathrm{Hg}$ in the left. There was no family history of glaucoma. Gonioscopy revealed narrow open angles, with a plateau iris of appearance. There was wide, deep physiological cupping of both optic discs and the visual fields were $\tilde{N}$ full. The coefficient of outflow facility, untreated, was 0.13 in the right eye and 0.17 in the left. $\omega$ A water-drinking test was positive. The intraocular pressures fluctuated between 20 and $25 \mathrm{~mm} . \mathrm{Hg}$. thereafter, and a gradual reduction in visual acuity took place due to lens opacities.

In June, 1967 , a flame-shaped haemorrhage was observed infero-temporally on the left disc, but $\$$ static visual field examination showed no defect. In May, 1968, the treated diurnal tension peaks were $20 \mathrm{~mm} . \mathrm{Hg}$ in both eyes and the optic discs remained unchanged. 


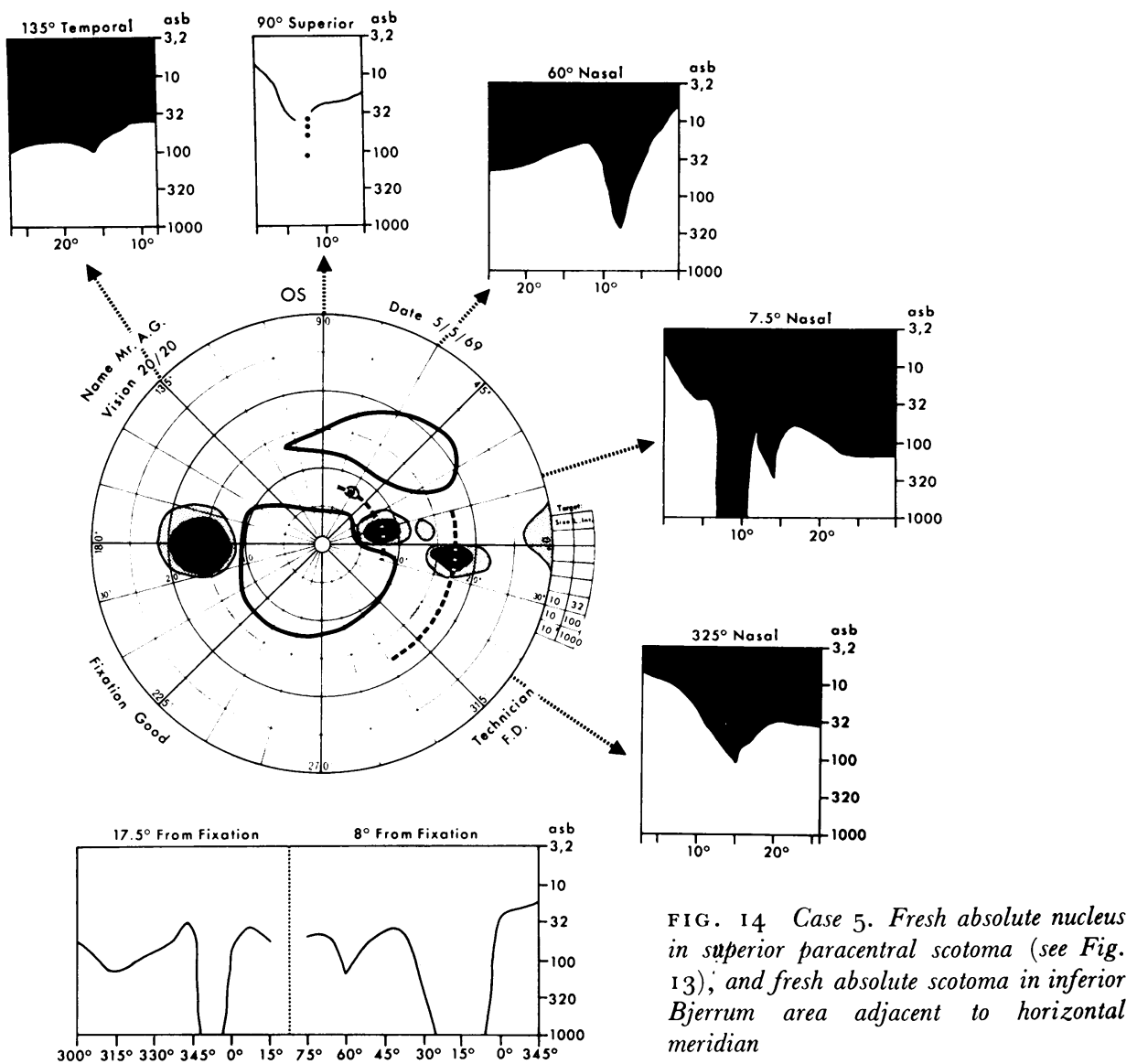

In March, 1970, a superficial haemorrhage was observed at the left disc, at 5 o'clock overlying the neuroretinal rim and peripapillary region. The right optic disc remained unchanged. The cup: disc ratio was 0.8 in the right eye and 0.7 in the left. There was no significant peripapillary atrophy. The arterioles showed slight sclerotic changes in both eyes. Static field examination revealed a small relative paracentral scotoma situated in the $2^{\circ}$ meridian, $34^{\circ}$ from fixation, and a nasal step (Fig. 16). At this time the diurnal tension peaks on therapy were $18 \mathrm{~mm} . \mathrm{Hg}$ in the right eye and $17 \mathrm{~mm} . \mathrm{Hg}$ in the left.

General assessment revealed no significant past history. There were no cardiovascular, cerebrovascular, or neurological symptoms or signs. The blood pressure was $170 / 90$ with no postural change. Repeated electrocardiograms showed evidence of an old atrio-septal myocardial infarct, unchanged since 1967 . The erythrocyte sedimentation rate was $49 \mathrm{~mm}$. in i hour. A temporal artery biopsy showed no pathological changes of temporal arteritis.

Case 7, a 72-year-old man with marked myopia, was found to have ocular hypertension in 1964 . The intraocular pressures were $30 \mathrm{~mm} . \mathrm{Hg}$ in the right eye and $35 \mathrm{~mm} . \mathrm{Hg}$ in the left. Gonioscopy revealed wide open angles. The optic discs showed suspicious cupping, but careful tangent screen visual field examination to $1 / 1000$ white target showed no defect. There was no family history of glaucoma. Initially, good control was achieved on 2 per cent pilocarpine, but additional therapy, including Diamox, became necessary. Control was erratic and in May, 1969, the diurnal tension peaks were $35 \mathrm{~mm} . \mathrm{Hg}$ in the right eye and $29 \mathrm{~mm} . \mathrm{Hg}$ in the left. The optic discs were unchanged and static and kinetic visual field examination showed no defects. 


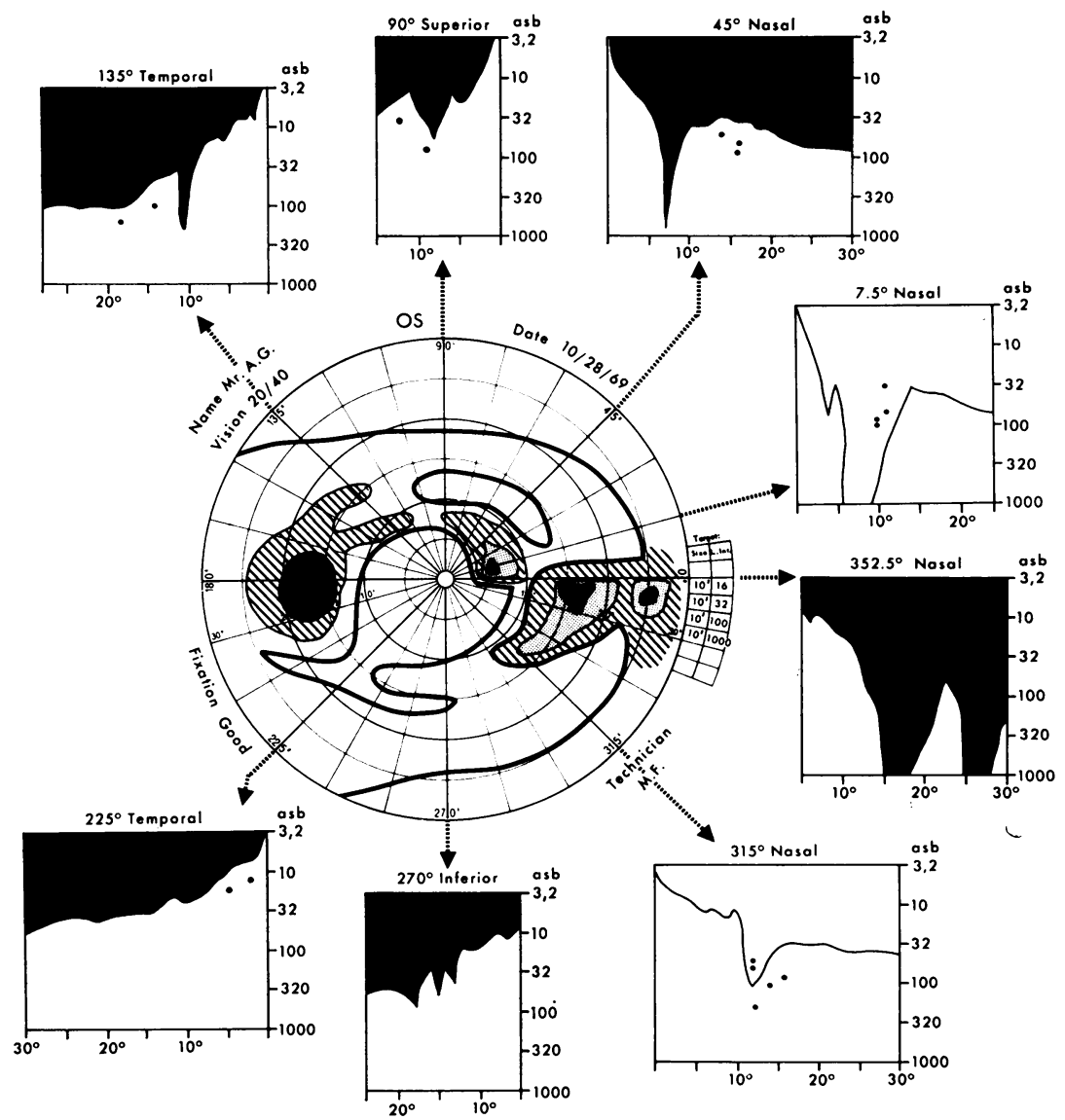

FIG. I5 Case 5. Fresh absolute nucleus adjacent to horizontal meridian in $30^{\circ}$ isopter
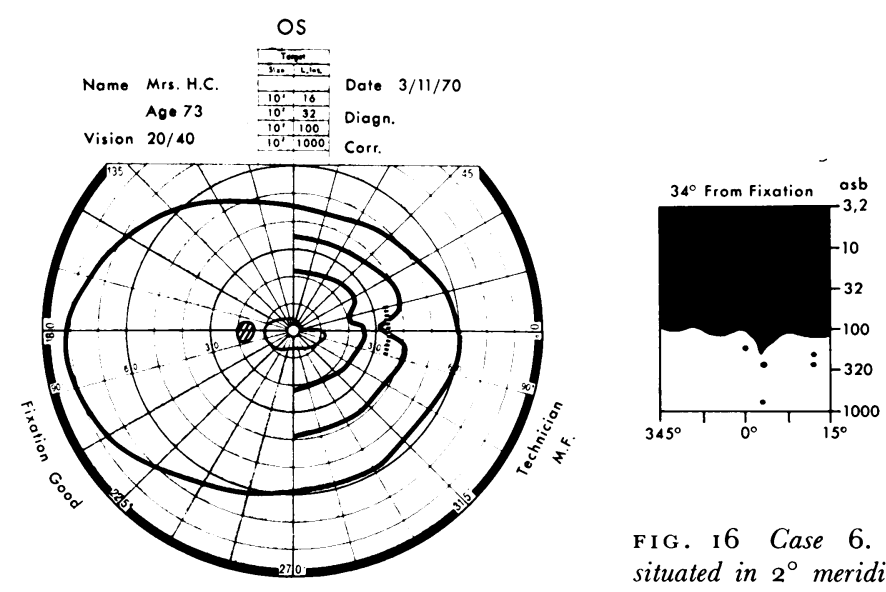

FIG. I6 Case 6. Small relative paracentral scotoma situated in $2^{\circ}$ meridian, $34^{\circ}$ from fixation seen in circular static perimetry accompanied by nasal steps in smaller isopters 
In January, 1970, examination showed that there was saucerization and transparent change in both optic discs which were surrounded by marked peripapillary atrophy. In the left disc there was a minute, deep haemorrhage in the neuroretinal rim at 2.30 o'clock. The intraocular pressures at this time were $26 \mathrm{~mm} . \mathrm{Hg}$ in the right eye and $22 \mathrm{~mm} . \mathrm{Hg}$ in the left. Static field examination of the left eye showed a lower nasal step in the central and peripheral isopters (Fig. I7).

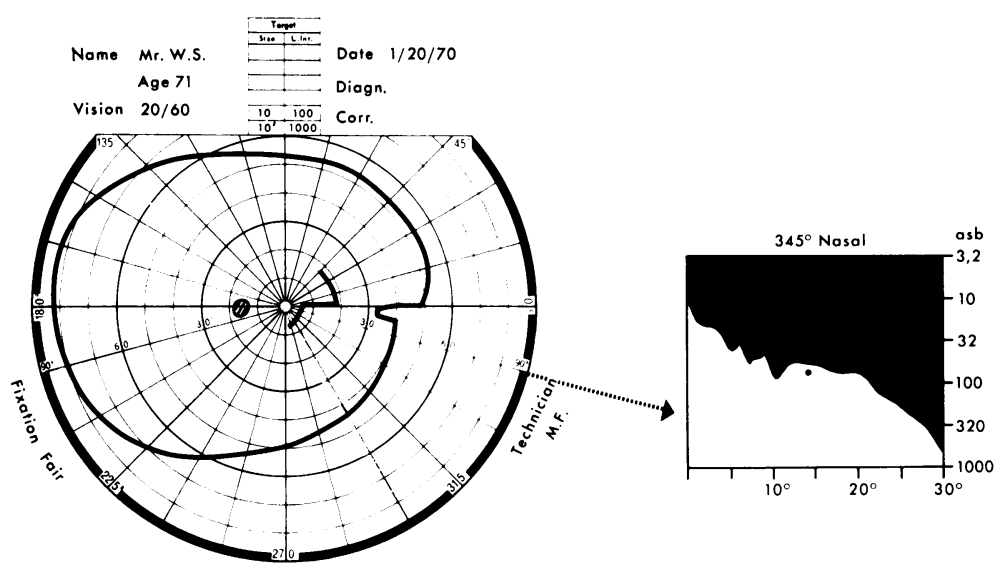

FIG. I 7 Case 7. Lower nasal step in central and peripheral isopters

General assessment revealed no significant past history and no symptoms of vascular or neurological disease. The blood pressure was $136 / 76$ with no postural change. The pulse was $68 / \mathrm{min}$. and ment lting. Aortic stenosis and mitral insufficiency were detected with moderate cardiac enlargefibrialibut no definite evidence of congestive heart failure. Systolic bruits were present over both internal carotid arteries, possibly conducted from the heart. The electrocardiogram showed a rapid ventricular rate with frequent premature ventricular contractions.

\section{SUMMARY}

These three patients showed ocular hypertension in which haemorrhages at the disc were accompanied by visual field defects of varying degree ranging from relative to multiple absolute defects heralding the change from ocular hypertension to chronic simple glaucoma.

\section{Summary of findings}

Some characteristics were shared by this group of patients. Three of them, at the outset, were classified as ocular hypertensives with intraocular pressures greater than $2 \mathrm{I} \mathrm{mm} . \mathrm{Hg}$, physiologically cupped optic discs, and full visual fields assessed by both static and kinetic perimetry. After the initial appearance of a haemorrhage in a sector of the disc, a corresponding nerve fibre bundle defect was plotted and the clinical diagnosis was changed to chronic simple glaucoma. Similar appearance of haemorrhages in sectors of the disc characterized the progression of chronic simple glaucoma in four patients.

The relevant features of these seven cases are listed in the Table (overleaf). Their ages ranged from 55 to 76 years, and a family history of glaucoma was present in two of them. The highest intraocular pressures recorded were well above the statistical limits of normality. The coefficients of outflow facility, when measured, were in the low range, even when recorded under medication. At the time when the disc haemorrhage was observed, the intraocular pressure in this group of patients was either within the normal limits or only 
Table Ischaemic optic neuropathy in chronic simple glaucoma

\begin{tabular}{|c|c|c|c|c|c|c|c|c|c|c|}
\hline \multirow{2}{*}{$\begin{array}{l}\text { Case } \\
\text { no. } \\
\overline{*_{\mathrm{I}}}\end{array}$} & \multirow{2}{*}{$\begin{array}{l}\text { Age } \\
(y r s)\end{array}$} & \multirow{2}{*}{$\begin{array}{l}\text { Sex } \\
\bar{M}\end{array}$} & \multicolumn{2}{|c|}{$\begin{array}{l}\begin{array}{l}\text { Highest } \\
\text { intraocular } \\
\text { pressure }\end{array} \\
\text { Right Left }\end{array}$} & \multicolumn{2}{|c|}{$\begin{array}{l}\text { Cup : Disc } \\
\text { ratio } \\
R: L\end{array}$} & \multirow{2}{*}{$\begin{array}{l}\begin{array}{l}\text { Blood } \\
\text { pressure }\end{array} \\
110 / 76\end{array}$} & \multirow{2}{*}{$\begin{array}{l}\text { Efficient } \\
\text { gradient }\end{array}$} & \multirow{2}{*}{$\begin{array}{l}\text { Systemic disease } \\
\text { Hypotension }\end{array}$} & \multirow{2}{*}{ Figures } \\
\hline & & & 31 & $3^{1}$ & $0 \cdot 6$ & $0 \cdot 7$ & & & & \\
\hline$*_{2}$ & 67 & $\mathrm{~F}$ & 30 & 30 & $0 \cdot 8$ & 0.9 & 190/1 06 & $\overline{87}$ & $\begin{array}{l}\text { Hypertension } \\
\text { Paroxysmal tachycardia }\end{array}$ & $3-5$, I 8 \\
\hline 3 & $5^{6}$ & $\mathbf{F}$ & 26 & 30 & 0.6 & $0 \cdot 8$ & $160 / 90$ & $\begin{array}{l}76 \\
74 \\
\end{array}$ & Myocardial infarcts & 6 \\
\hline 4 & 64 & $\mathrm{~F}$ & 28 & 26 & $0 \cdot 7$ & $0 \cdot 7$ & $15^{0 / 90}$ & $\begin{array}{l}73 \\
77\end{array}$ & $\begin{array}{l}\text { Past history of } \\
\text { peptic ulcer } \\
\text { Glucose tolerance test positive } \\
\text { Hypercoagulable state }\end{array}$ & $7-1 \mathrm{I}$ \\
\hline 5 & 76 & $\mathbf{M}$ & 25 & 25 & 0.7 & $0 \cdot 7$ & I 6o/90 & $\begin{array}{l}65 \\
72\end{array}$ & $\begin{array}{l}\text { Myocardial infarction } \\
\text { Basilar artery insufficiency }\end{array}$ & $12-15$ \\
\hline 6 & 73 & $\mathrm{~F}$ & 25 & 25 & $0 \cdot 8$ & $0 \cdot 7$ & $170 / 90$ & $\begin{array}{l}81 \\
78\end{array}$ & Myocardial infarction & I6 \\
\hline 7 & 72 & $\mathbf{M}$ & 35 & 35 & 0.7 & 0.7 & 1 $36 / 76$ & $\begin{array}{l}53 \\
32\end{array}$ & $\begin{array}{l}\text { Aortic stenosis } \\
\text { Mitral insufficiency } \\
\text { Fibrillating pulse }\end{array}$ & 17 \\
\hline
\end{tabular}

* Family history of glaucoma

slightly elevated. A comparison of the cup: disc ratios showed that the wide cupping w approximately equal in both eyes. A high incidence of moderate to marked peripapillar atrophy was observed. The erythrocyte sedimentation rate was recorded in six of the seven patients and no significant elevation was found. A temporal artery biopsy was carried $\stackrel{\varrho}{\mathbb{D}}$

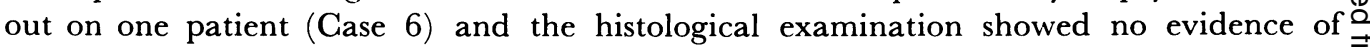
giant cell arteritis. Evidence of vascular disease was seen in six of the seven patients; hypertension and ischaemic heart disease predominated. One of the patients had a positive glucose tolerance test and increased platelet adhesiveness. The only patient without significant vascular disease had a family history of glaucoma and a low blood pressure.

DESGRIPTION OF HAEMORRHAGE ON A SECTOR OF THE DISC

The disc haemorrhages observed were either superficial or deep, the former appearing 0 to predominate. The superficial haemorrhages were characteristically linear or flameshaped and spread into the peripapillary retina. Some of these haemorrhages were very fine and could easily have been mistaken through the small pupil for a congested No blood vessel, dilated capillaries, or neovascularization. Deep haemorrhages were round and irregular in shape, probably because of the directional change of the nerve fibres on the disc. Deep haemorrhages were occasionally observed in the peripapillary region. The haemorrhages were commonly situated in the positions of the arcuate nerve fibre bundles. The haemorrhages were usually fleeting, lasting from a few days to several weeks. As absorption proceeded, fragmentation of the haemorrhage could be observed, and in one case this was followed by local atrophy of the neuroretinal rim. No local 


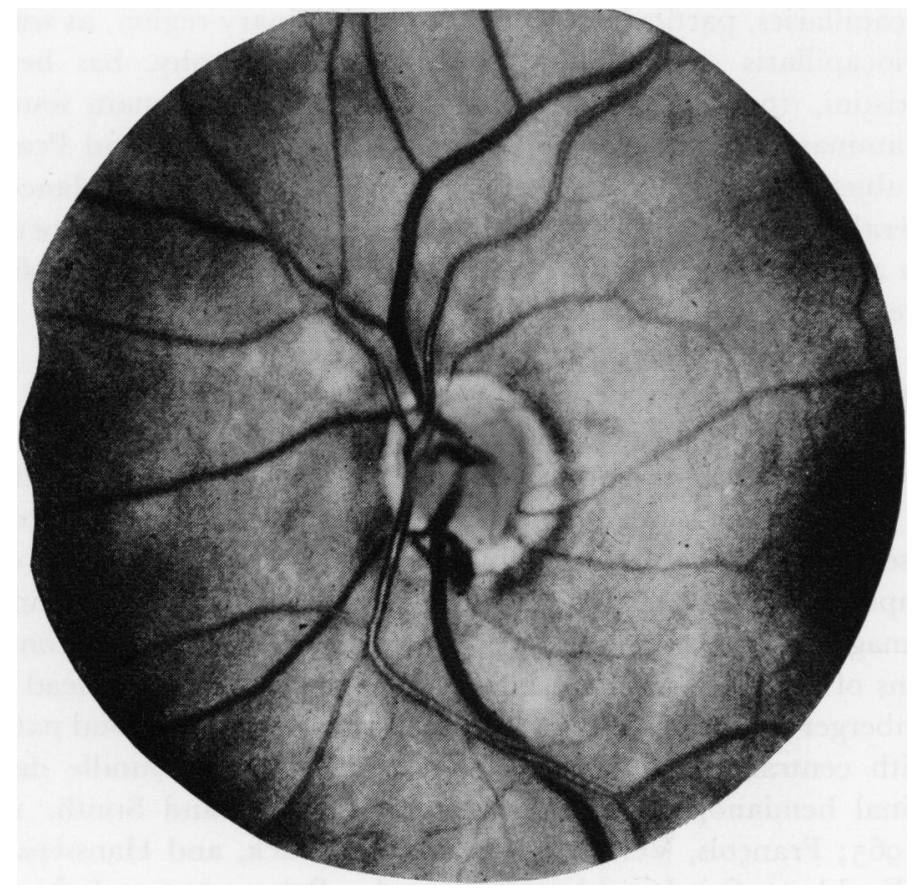

FIG. 18 Case 2. Leading to fresh paracentral scotoma (shown in Fig. 5) Haemorrhage on inferior portion of disc

swelling accompanied the haemorrhage except in one case in which the appearance resembled a local swelling of nerve fibres but not a soft exudate. No microaneurysms were seen and there were no signs of emboli or sheathing in any of the retinal vessels.

\section{PROGRESSION OF FIELD DEFEGTS}

The appearance of the disc haemorrhage was accompanied by a step-like progression of field defects. These abrupt changes were associated with, but not produced by, a linear haemorrhage on the disc. In all seven cases, the field defect corresponded to the arcuate nerve fibre bundles at the neuroretinal rim in the position of the haemorrhage. In some of the other cases in our series of thirty patients no field defect could be plotted to correspond to the disc haemorrhage, but the possibility remained that the nerve fibre bundle defect was too small to detect even by the present techniques. The onset and progression of visual field defects resembled the sequence described by Aulhorn and Harms (1966). The following fresh defects were observed:

(I) An absolute paracentral scotoma close to fixation.

(2) An absolute paracentral scotoma in the Bjerrum area adjacent to the horizontal meridian.

(3) An absolute scotoma adjacent to the horizontal meridian between the $30^{\circ}$ and $65^{\circ}$ isopters.

(4) An absolute nucleus in a previously relative paracentral scotoma.

(5) The extension of an absolute arcuate-shaped paracentral scotoma.

(6) The appearance of a completely new absolute arcuate scotoma.

\section{Discussion}

Glaucomatous atrophy of the nerve head is characterized by a general reduction in the capillary circulation (Elschnig, I 928; Cristini, I951 ; François and Neetens, I966; Hayreh and Walker, 1967; Oosterhuis and Gortzak-Moorstein, 1970; Hayreh, I969). A reduction 
in the number of capillaries, particularly severe in the laminary region, as well as obliteration of the choriocapillaris and peripapillary choroidal atrophy, has been reported pathologically (Cristini, I95I). These choroidal vessels are the main source of blood supply to the prelaminar plexus (Hayreh, I969; Henkind, Charles, and Pearson, I970). and are not only subject to degenerative changes in chronic open-angle glaucoma but are also the most vulnerable portion of the choroidal circulation when the intraocular pressure is acutely raised in animals (Hayreh and Perkins, I969; Ernest and Potts, I968) and man (Blumenthal, Gitter, Best, and Galin, 1970). Clinically, notching of the neuroretinal rim, especially in the areas corresponding to the arcuate nerve fibres, is a feature of glaucomatous cupping (Kronfeld, I968).

In a previous communication (Drance and Begg, 1970) it was suggested that the haemorrhage on the neuroretinal rim of the optic disc and the fresh field defect in these glaucomatous cases was the result of a segmental ischaemic optic neuropathy occurring as a result of small vessel disease, perhaps at a capillary level. This assumption can be supported by the symptomless, discrete nature of the papillary haemorrhage and field defect characterizing damage to the arcuate nerve fibre bundles in marked contrast to the symptoms and signs of total and subtotal infarction of the optic nerve head (Miller and Smith, I966; Ellenberger and Netsky, 1968). When infarction is subtotal patients almost always present with central visual failure or severe nerve fibre bundle damage often producing altitudinal hemianopia. Arcuate scotoma (Miller and Smith, I966; Hoyt, 1962; Enoksson, I965; François, Verriest, Neetens, de Rouck, and Hanssens, 1962) and central scotoma (Foulds, 1969) have been reported. Pale oedema of the nerve head is usually, but not necessarily, present; it was not observed in the present series, perhaps on account of its symptomless or transient nature when associated with a discrete infarction Segmental infarction followed by atrophy has been reported in ischaemic optic neura pathy (Enoksson, I965), and following an embolic occlusion on the optic disc (Harrington I964b), or as a probable embolic occlusion of a posterior ciliary artery (Hoyt, I962): Observation of some of the patients in this series has shown that the sectoral haemorrhage was eventually followed by circumscribed notching of the neuroretinal rim resulting in localized enlargement of the cup and the appearance of atrophy.

We could find no mention in the literature of symptomless arcuate scotoma caused by acute ischaemic changes at the optic disc in eyes with ocular hypertension. Haemorrhage on a sector of the disc accompanied by a corresponding fresh nerve fibre bundle defect was shown in three of the cases described, indicating the transition of ocular hypertension to chronic simple glaucoma.

In a pathological study of optic nerves from twenty cadavers, Ellenberger and Netsky (1968) found that the arterial supply of the optic nerve is subject to atherosclerosis and arteriosclerosis no less than other vessels of similar size. These degenerative vascular changes have been regarded as important aetiological factors in total and subtotal infarction of the optic nerve head (Miller and Smith, r966; Ellenberger and Netsky, I968; François and others, I962; Foulds, 1969). In these reports, hypertension and cardiac disease was common, and diabetes was an occasional finding. Arteriograms that have been carried out in patients with ischaemic optic neuropathy have been normal, including filling of the ophthalmic artery (David, 1967). This clinical entity comes to attention because of visual symptoms, pale oedema of the disc, usually multiple flame-shaped haemorrhages, and usually severe nerve fibre bundle damage. The ischaemic optic neuropathy which we report is symptomless, small, and discrete. Oedema has not been seen, either because of the very small area involved or because it was only very transient. 
A vascular, neurological, and laboratory assessment of the patients showed no evidence of circulatory decompensation or vasculitis, but there were signs of extraocular small vessel disease. In the present series, small vessel disease was associated either with ischaemic heart disease or hypertension, or a positive glucose tolerance test, or a combination of these factors. A hypercoagulable state may be another contributory factor. The only patient without significant vascular disease had a family history of glaucoma and a very low blood pressure.

Some of the known deleterious and favourable factors which seem to influence perfusion of the optic nerve head have been briefly mentioned in a previous report (Drance and Begg, 1970). Patients with marked glaucoma-like damage to the optic nerve head and advanced visual field loss, with or without elevated intraocular pressure, have been shown, in retrospective studies, to have a low "diastolic perfusion pressure" as measured by ophthalmodynamography (Johnson and Drance, I968) or a history of an acute haemodynamic crisis. Patients showing progressive field change were thought to have a low "efficient gradient" as measured by ophthalmodynamometry (Lobstein, 1968). In our group of patients, at the time when the disc haemorrhage and field loss were observed, the intraocular pressure, under treatment, was either within normal limits or only slightly elevated. Using the ophthalmodynamometric technique of Weigelin and Lobstein (Weigelin and Lobstein, I963), no deficit between expected and obtained diastolic and mean ophthalmic artery pressures was present, nor was there any significant dynamometric difference between the two sides. Using the concept of "efficient gradient" (Lobstein, I968), this did not suggest an impaired perfusion pressure except in one patient with a very low blood pressure; this suggests that the ischaemic optic neuropathy was probably related to small vessel disease, a theory which is supported by the frequency of extraocular small vessel disease found on general assessment of many of these patients.

\section{Summary}

The occurrence of discrete, recurrent, and sometimes bilateral haemorrhages in sectors of the disc, in the region of the arcuate nerve fibres, associated with fresh absolute field defects in the Bjerrum area was thought to characterize symptomless ischaemic optic neuropathy. These changes were observed in three patients with ocular hypertension, marking the transition to chronic simple glaucoma. A similar sequence marked the progression of field loss in four patients with chronic simple glaucoma. The general and neurovascular assessment of the patients, their level of intraocular pressure at the time of the field loss, and the ophthalmodynamometric findings suggested that the ischaemic optic neuropathy in this group of patients was probably due to small vessel disease, producing inadequate perfusion of the optic nerve head. Adverse perfusion pressures were seen in only some of this group of patients, which suggests that there are many causes for poor perfusion at the optic nerve head. An imbalance between intraocular pressure and vascular pressure, while common, is not the only cause of a nerve fibre bundle infarction indistinguishable from that found in chronic simple glaucoma.

We wish to express our thanks to Dr. W. R. Morton for letting us study some of his patients and to Mrs. M. Fairclough and Miss J. Bryett for the excellence of the fields.

\section{References}

ARMALy, м. F. (I969) Invest. Ophthal., 8, 105

AUlhorn, E., AND HARMS, H. (I966) "Early Visual Field Defects in Glaucoma", in "Glaucoma:

Symposium in Tutzing Castle, 1966", Pp. I 5 1. Karger, Basel 
BEGG, I. S., DRANCE, S. M., and sWeEney, v. P. (1970). Canad. J. Ophthal., 5, 321

blumenthal, м., gitter, к. A., Best, м., and galin, м. A. (1970) Amer. J. Ophthal., 69, 39

CRISTINI, G. (1951) Brit. J. Ophthal., 35, I I

DAvid, N. J. (1967) "Ocular Clues to Stroke Mechanisms", in "Neuro-ophthalmology; Sym-

posium," ed. J. Lawton Smith, vol. 3, p. 294. Mosby, St. Louis

DRANCE, s. M., and BEGG, I. s. (1970) Canad. F, Ophthal., 5, I 37

DUKE-ELDER, s. (1962) Trans. ophthal. Soc. U.K., 82, 307

ellenberger, c., and Netsky, m. g. (1968) F. Neurol. Neurosurg. Psychiat., 31, 6 o6

elschnig, A. (1928) in "Handbuch der speziellen pathologischen Anatomie und Histologie",

ed. F. Henke and O. Lubarsch, vol. 2, "Auge”, pt. 1, p. 873. Springer, Berlin

ENOKsson, P. (1965) Acta ophthal. (Kbh.), Suppl. 82, p. I I

ERNEST, J. T., and POTTS, A. м. (1968) Amer. F. Ophthal., 66, 380

Feldman, f., SWEEney, v. P., and DRANCE, s. m. (1969) Canad. F. Ophthal., 4, $35^{8}$

Foulds, w. s. (1969) "Ischaemic Optic Neuropathy", in "The William MacKenzie Centenary

Symposium on the Ocular Circulation in Health and Disease", ed. J. S. Cant, p. I36. Kimpton,

London

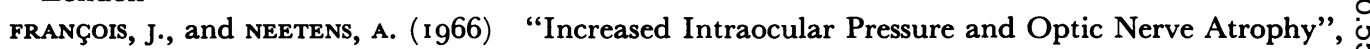

p. I 30 . Junk, Den Haag

r95, 830

GAFNER, F., and GOLDMANN, H. (1955) Ophthalmologica (Basel), 130, 357

hARRINGTON, D. O. (1959) Amer. J. Ophthal., 47, 177

(1964a) Trans. Amer. ophthal. Soc., 62, 324

(1964b) "The Visual Fields", 2nd ed. Mosby, St. Louis

HAYREH, s. s. (1969) Brit. J. Ophthal., 53, 721

and PERKins, E. s. (I969) "Clinical and experimental studies on the circulation at the

optic nervehead", in "The William MacKenzie Centenary Symposium on the Ocular Circulation .

in Health and Disease", Proceedings of a Symposium held at the Royal College of Physicians and

Surgeons of Glasgow, Sept. 23-24, 1968, ed. J. S. Cant, p. 71. Kimpton, London and WAlKer, w. м. (1967) Amer. J. Ophthal., 63, 982

heNkind, P., CHARLES, N. C., AND PEARSON, J. (1970) Ibid., 69, 78

HOYT, w. F. (1962) Bull. Johns Hopk. Hosp., 111, 57

JOHNSON, D. G., and DRANCE, s. M. (1968) Canad. F. Ophthal., 3, I 49

KRONFELD, P. C. (1968) "The Optic Nerve", in "Symposium on Glaucoma. Trans. New Orleans

Acad. Ophthal., 1967". Mosby, St. Louis

LOBSTEIN, A. (1968) "Factors affecting the Susceptibility of the Glaucomatous Eye to Raised Intra-

ocular Pressure," in "First South American Glaucoma Symposium, Argentina, 1966". Mod.

Probl. Ophthal., 6, 73. Karger, Basel

MILlER, G. R., and SMITH, J. LAWTON (1966) Amer. F. Ophthal., 62, I03

Oosterhuis, J. A., and GORTZAK-MOoRstein, N. (1970) Ophthalmologica (Basel), 160, 33 I

TRAQUAIR, H. M. (1944) Trans. ophthal. Soc. U.K., 64, 3

WEIGRLIN, F., and LOBSTEIN, A. (1963) "Ophthalmodynamometry". Karger, Basel 